\title{
Focal Segmental Glomerulosclerosis Tip Lesion Variant
}

National Cancer Institute

\section{Source}

National Cancer Institute. Focal Segmental Glomerulosclerosis Tip Lesion Variant. NCI

Thesaurus. Code C123054.

A variant of FSGS characterized by scarring of the glomerulus adjacent to the orig in of the proximal convoluted tubule; this occurs in the absence of collapsing and perihilar FSGS. (D'Agati VD, et al. "Pathologic Classification of Focal Segmental Glomerulosclerosis: A Working Proposal." Am J Kidney Dis 43.2 (2004): 368-82.) 